\title{
A randomized comparative study of efficacy and safety of saroglitazar with fenofibrate in diabetic dyslipidemic patients on metformin and glimeperide
}

\author{
Syed Mohsin Ahmed ${ }^{1 *}$, Momin Mohd. Abdul Mujeeb²
}

\begin{abstract}
${ }^{1}$ Department of Pharmacology, Mysore Medical College and Research Centre, Irwin Road, Mysore 570001, Karnataka, India

${ }^{2}$ Department of Pharmacology, Grand Government Medical College, Mumbai, Maharashtra, India
\end{abstract}

Received: 24 March 2017 Accepted: 05 April 2017

\section{*Correspondence to:}

Dr. Syed Mohsin Ahmed, Email: syedmohsin1974.sa@ gmail.com

Copyright: (C) the author(s), publisher and licensee Medip Academy. This is an openaccess article distributed under the terms of the Creative Commons Attribution NonCommercial License, which permits unrestricted noncommercial use, distribution, and reproduction in any medium, provided the original work is properly cited.

\begin{abstract}
Background: This study was conducted to compare the efficacy and safety of saroglitazar with fenofibrate in Indian diabetic dyslipidemic patients who were on Metformin and Glimepiride.

Methods: Adults patients with diabetic dyslipidaemia fulfilling the inclusion criteria were randomized in two groups. Group A patients received metformin (1000 mg/ day) + Glimepiride (4 mg/day) with fenofibrate (160 mg/day), while group B patients received metformin $(1000 \mathrm{mg} /$ day $)+$ Glimepiride (4 mg/day) with saroglitazar (4 mg/day). Glycosylated haemoglobin (HbA1C), triglyceride (TG), LDL- cholesterol (LDL-C), HDL-cholesterol (HDL-C) levels were measured at baseline and at 12 weeks. Fasting plasma glucose (FPG) and post prandial plasma glucose (PPPG) were measured at baseline and at 4, 8 and 12 weeks.

Results: There was a significant reduction in TG and HbA1C levels at 12 weeks from the baseline value $(\mathrm{p}=0.001)$ in both groups. However, there was no significant reduction in TG between the groups at 12 weeks but HbA1C levels in group B decreased significantly compared to group A at 12 weeks. Also, there was a significant reduction in FPG and PPPG levels at 4, 8 and 12 weeks in both groups from their baseline values $(\mathrm{p}=0.001)$. The reduction in FPG and PPPG levels in group B was statistically significantly compared to group A at every interval. There was statistically significant change in LDL-C and HDL-C at 12 weeks from baseline in both the groups. Also, there was significant rise in HDL-C in group B when compared to group A.

Conclusions: Group B patients on saroglitazar with metformin and Glimepiride showed a significant reduction in $\mathrm{HbA1C}$, FPG and PPG levels compared to group A patients on fenofibrate with metformin and Glimepiride.
\end{abstract}

Keywords: Diabetes mellitus, Diabetic dyslipidaemia, Fenofibrate, Saroglitazar

\section{INTRODUCTION}

Diabetes is fast gaining the status of a potential epidemic in India with more than 62 million diabetic individuals currently diagnosed with the disease. ${ }^{1,2}$ It is predicted that by 2030 diabetes mellitus may afflict up to 79.4 million individuals in India. ${ }^{3,4}$ Diabetic patients have an increased cardiovascular risk. This risk gets exaggerated by dyslipidaemia. Diabetic Dyslipidaemia (DD) is characterized by elevated fasting and post prandial plasma glucose along with increased triglyceride (TG), LDL-cholesterol (LDL-C) and decreased HDLcholesterol (HDL-C) levels. Increased serum TG and low HDL-C often precede the onset of Type- 2 diabetes mellitus (DM). In addition, a qualitative change in LDL particles, producing a small dense LDL-C particles (sdLDL-C) whose membrane carries supra-normal amounts of free cholesterol which are more susceptible to oxidation rendering them more atherogenic. These changes in lipid profile represent the major link between 
diabetes and the increased cardiovascular risk of diabetic patients. ${ }^{5,6}$

Diabetes and its accompanying dyslipidaemia are managed by a variety of permutations and combinations of oral anti-diabetic agents (ADAs) and hypolipidemic drugs. As far as dyslipidaemia is concerned, statins at best are able to benefit $20-30 \%$ patients only. Fibrates as well as Niacin have also not succeeded in bridging the therapeutic gap mainly due to the myotoxicity exerted by the former and lack of efficacy of the latter in all patients. $^{7,8}$

To address this gap in therapy the Peroxisome Proliferator-Activated Receptors (PPAR)- $\alpha / \gamma$ agonists were developed. These molecules could correct both the dyslipidaemia as well as hyperglycaemia in diabetic dyslipidaemia. PPAR- $\alpha$ agonists (fenofibrate) and PPAR$\gamma$ agonist (pioglitazone) are approved for dyslipidaemia and type-2 DM respectively. However, the use of pioglitazone is associated with problems such as fluid retention, weight gain and congestive cardiac failure. ${ }^{9}$ Hence, the dual PPAR-a $/ \gamma$ agonist was developed with an aim to control both lipid and blood glucose parameters. This dual agonists can help activate both PPAR- $\alpha$ and PPAR- $\gamma$ receptors simultaneously, thus controlling, dyslipidaemia and hyperglycemia and in addition, help reduce the risk of weight gain that is stimulated by PPAR- $\gamma$ activation. This lack of weight gain was first observed with the use of Fibrates that not only provided hypolipidemic effects but also reduced body weight without affecting intake of food. ${ }^{10}$

Saroglitazar is the first approved dual PPAR- $\mathrm{a} / \gamma$ agonist for patients suffering from Diabetic dyslipidemia, which has shown efficacy in improving both, the lipid as well as the glycaemic parameters, with an excellent safety profile. ${ }^{11}$ Saroglitazar was approved by Drug Controller General of India (DCGI) for launch in India in June $2013 .^{12}$ The present study was designed to compare the effectiveness and safety of add on therapy of saroglitazar and fenofibrate with metformin plus glimepiride in Diabetic dyslipidemic patients.

Trails conducted so far in India have evaluated efficacy of saroglitazar on lipid profile and glycaemic parameters of patients with dyslipidaemia and diabetic dyslipidaemia. There are very limited studies regarding the efficacy of add on therapy of saroglitazar to the antidiabetic treatment regimen. Against this background, the present study was designed to compare the effectiveness and safety of add on therapy of saroglitazar and fenofibrate with metformin and glimepiride in Indian patients with diabetic dyslipidaemia.

\section{METHODS}

A prospective, randomized, open labeled, parallel group study was conducted at Grand Government College, Mumbai after taking written informed consent from the patients and Institutional ethical committee clearance. Subjects were recruited from diabetic centers in Mysore and the study was conducted between September 2016 and November 2016.

The objective of the study was to evaluate the influence of Fenofibrate and Saroglitazar on Lipid parameters (i.e. TG, LDL-C and HDL-C after 12 weeks from baseline) and on glycaemic parameters (i.e. HbA1C after 12 weeks from baseline, FPG and PPG at 4, 8 and 12 week intervals).

Difference of means to be detected was set at $10 \%$. Considering the true mean difference between two treatment groups as zero and the expected standard deviation of $10 \%$ in the study population, $80 \%$ power and margin of error $=0.05$, the number of patients required in each treatment group was 17 . The sample size was calculated with the set inclusion and exclusion criteria by using the formula:

$$
\begin{aligned}
S & =\frac{Z^{2} \times P \times q}{d^{2}} \\
& =\frac{1.96 \times 1.96 \times 0.25 \times 0.975}{0.05 \times 0.05} \\
& =33
\end{aligned}
$$

\section{Inclusion criteria}

- Adult subjects of either sex, aged between 18-70 years

- Newly diagnosed Type 2 Diabetic Dyslipidemic patients with FPG $\geq 126 \mathrm{mg} / \mathrm{dl}, \mathrm{PPG} \geq 200 \mathrm{mg} / \mathrm{dl}$ with plasma triglyceride level $\geq 150 \mathrm{mg} / \mathrm{dl}$ and $\mathrm{HbA} 1 \mathrm{C}$ $\geq 6.5$ and $\leq 9$

- None of the patients received any hypolipidemic agent within last six months

- Patients with normal liver and renal parameters

\section{Exclusion criteria}

- Patients with fasting plasma glucose (FPG) $>250 \mathrm{mg} / \mathrm{dl}$, post-prandial plasma glucose (PPG) $>350 \mathrm{mg} / \mathrm{dl}$, LDL-C >130mg/dl

- Type 2 Diabetics requiring insulin therapy

- Type 2 Diabetics requiring triple drug therapy

- Presence of serious co-morbid conditions such as severe uncontrolled hypertension, renal, hepatic or cardiac impairment

- Presence of any absolute contraindications like pregnancy, lactation, lactose intolerance and hypersensitivity to any of the drugs or their components

- Subjects with Type 1 Diabetes mellitus and Diabetic ketoacidosis 
- Subjects on other drugs with known drug interactions with the study drugs and that are likely to alter lipid profile and glycaemic status.

\section{Primary end point}

- Change in Triglyceride levels after 12 weeks from baseline

- Change in HbA1C levels after 12 weeks from baseline

\section{Secondary end points}

- Change in HDL-C, LDL-C levels after 12 weeks from baseline

- Change from baseline in fasting plasma glucose (FPG) levels at 4, 8, 12 weeks

- Change from baseline in post prandial plasma glucose (PPG) levels at 4, 8, 12 weeks

- Any Untoward Adverse Effects Observed namely hypoglycemia

Each patient was evaluated for 12 weeks. Patients were initially screened clinically and biochemically on day 0 and at the follow up visits on weeks 4,8 and 12 . HbA1C and lipid profile estimations were made on day 0 and week 12. FPG, PPPG were repeated at baseline and on all subsequent visits i.e. at 4,8 and 12 weeks.

Patients included in the study were randomly allocated in two different treatment groups using computer generated random tables.

Patients included in group A received metformin $500 \mathrm{mg}$ twice daily plus glimepiride $2 \mathrm{mg}$ twice daily (USV Limited, Mumbai) and fenofibrate $160 \mathrm{mg}$ once daily (USV Limited, Mumbai).

Similarly, patients included in group B received metformin $500 \mathrm{mg}$ twice daily plus glimepiride $2 \mathrm{mg}$ twice daily (USV Limited, Mumbai) and saroglitazar (Zydus discovery, Cadila Healthcare Ltd., Ahmadabad) 4 $\mathrm{mg} /$ day.

Study medications were dispensed thrice during the study period: First during baseline visit (study medication given for 4 weeks) and next during week 4 and week 8 (each time for 4 weeks). Patients in group A were advised to take metformin $500 \mathrm{mg}$ plus glimepiride $2 \mathrm{mg}$ tablets orally twice daily 20 minutes before food and one fenofibrate $(160 \mathrm{mg})$ tablet after breakfast. Patients in group B were advised to take metformin $500 \mathrm{mg}$ plus glimepiride $2 \mathrm{mg}$ orally twice daily before food and one saroglitazar (4mg) tablet after breakfast for the 12 week study period.

Compliance was assessed using the traditional pill count method at each follow-up visit. Patients with worsening clinical conditions or rising plasma glucose level were decided to be withdrawn prematurely from the study. All patients were advised to quit smoking and consumption of alcohol during the study period. Patients were monitored continuously throughout the study for any adverse event (AE). All adverse effects were to be reported as per the Pharmacovigilence Programme of India (PVPI) to Grand Government Medical College, pharmacovigilence Center Mumbai, India.

\section{Statistical analysis}

Results were analysed by descriptive statistics calculating the mean values, the standard deviation, the standard error, repeated measures ANOVA and paired ' $t$ ' test for intra group comparison and by unpaired ' $t$ ' test for intergroup comparison. The p-value $<0.05$ was considered to be statistically significant.

\section{RESULTS}

The subjects included in the above study had no statistically significant difference in the baseline values of triglycerides, HbA1C, FPG, PPG, LDL-C and HDL-C. After treatment, TG and $\mathrm{HbA} 1 \mathrm{C}$ levels significantly decreased at week 12 from their respective baseline values ( $p=0.001$ i.e. highly significant) in both group $A$ and group B. On inter group analysis there was no statistically significant change in TG between groups A and $\mathrm{B}$ but there was statistically significant change in $\mathrm{HbA} 1 \mathrm{C}$ between groups $\mathrm{A}$ and $\mathrm{B}$ at 12 weeks.

Table 1: Baseline triglyceride, glycosylated haemoglobin, fasting plasma glucose, postprandial plasma glucose, LDL- cholesterol and HDLcholesterol levels.

\begin{tabular}{|llll|}
\hline Parameters & $\begin{array}{l}\text { Group A } \\
\text { (0- day) } \\
(\mathbf{M}+\mathbf{G}+\mathbf{F})\end{array}$ & $\begin{array}{l}\text { Group B } \\
(\mathbf{0}-\text { day }) \\
(\mathbf{M}+\mathbf{G}+\mathbf{S})\end{array}$ & $\begin{array}{l}\text { P - } \\
\text { value }\end{array}$ \\
\hline $\begin{array}{l}\text { Triglyceride } \\
(\mathrm{mg} / \mathrm{dl})\end{array}$ & $262.82 \pm 92.43$ & $264.05 \pm 85.38$ & $\begin{array}{l}0.968 \\
(\mathrm{NS})\end{array}$ \\
\hline HbA1C $(\%)$ & $8.0212 \pm 0.25$ & $8.1024 \pm 0.52$ & $\begin{array}{l}0.567 \\
(\mathrm{NS})\end{array}$ \\
\hline $\begin{array}{l}\text { FPG } \\
(\mathrm{mg} / \mathrm{dl})\end{array}$ & $137.11 \pm 8.22$ & $136.29 \pm 7.73$ & $\begin{array}{l}0.766 \\
(\mathrm{NS})\end{array}$ \\
\hline $\begin{array}{l}\text { PPG } \\
(\mathrm{mg} / \mathrm{dl})\end{array}$ & $227.52 \pm 9.64$ & $237.41 \pm 26.39$ & $\begin{array}{l}0.157 \\
(\mathrm{NS})\end{array}$ \\
\hline $\begin{array}{l}\mathrm{LDL}-\mathrm{C} \\
(\mathrm{mg} / \mathrm{dl})\end{array}$ & $117.00 \pm 11.51$ & $117.88 \pm 11.78$ & $\begin{array}{l}0.827 \\
(\mathrm{NS})\end{array}$ \\
\hline $\begin{array}{l}\mathrm{HDL}-\mathrm{C} \\
(\mathrm{mg} / \mathrm{dl})\end{array}$ & $54.11 \pm 8.03$ & $52.17 \pm 6.79$ & $\begin{array}{l}0.452 \\
(\mathrm{NS})\end{array}$ \\
\hline
\end{tabular}

- TG= Triglyceride, HbA1C = Glycosylated haemoglobin, FPG $=$ Fasting plasma glucose, $\mathrm{PPG}=$ Postprandial plasma glucose, LDL-C $=$ LDL- cholesterol, HDL-C $=$ HDL-cholesterol

- (mean \pm standard deviation) of groups $\mathrm{A}$ and $\mathrm{B}$ and their Pvalues

Post treatment the change in FPG and PPG at weeks 4, 8 and 12 compared to their pretreatment values $(\mathrm{P}=0.001)$ in both groups was statistically significant and the fall 
was significantly more in group $\mathrm{B}$ patients when

compared to group A patients.

Table 2: Changes in triglyceride and HbA1C levels in group a and group B at week 12 versus week 0.

\begin{tabular}{|lllllll|}
\hline Parameter & Group A & & & Group B & \\
& Week 0 & Week 12 & P value & Week 0 & Week 12 & P value \\
\hline TG (mg/dl) & $262.82 \pm 92.43$ & $118.52 \pm 42.36$ & $0.001(\mathrm{HS})$ & $264.05 \pm 85.38$ & $107.88 \pm 35.86$ & $0.001(\mathrm{HS})$ \\
\hline HbA1C $(\%)$ & $8.02 \pm 0.25$ & $6.69 \pm 0.22$ & $0.01(\mathrm{HS})$ & $8.10 \pm 0.52$ & $5.54 \pm 0.35$ & $0.001(\mathrm{HS})$ \\
\hline
\end{tabular}

- HS: highly significant

- Statistical test used was paired t-test.

Table 3: Triglyceride and HbA1C levels in group A and $B$ at week 12.

\begin{tabular}{|llll|} 
Parameters & $\begin{array}{l}\text { Group A } \\
\text { Week - 12 }\end{array}$ & $\begin{array}{l}\text { Group B } \\
\text { Week - 12 }\end{array}$ & $\begin{array}{l}\text { P - } \\
\text { value }\end{array}$ \\
$\begin{array}{l}\text { Triglyceride } \\
\text { (mg/dl) }\end{array}$ & $118.52 \pm 42.36$ & $107.88 \pm 35.86$ & $\begin{array}{l}0.435 \\
\text { (NS) }\end{array}$ \\
\hline HbA1C (\%) & $6.69 \pm 0.22$ & $5.54 \pm 0.35$ & $\begin{array}{l}0.001 \\
\text { (HS) }\end{array}$ \\
\hline
\end{tabular}

- NS: not significant, HS: highly significant

- Statistical test used was unpaired t-test.
The levels of LDL-C showed a statistically significant fall and the levels of HDL-C statistically significant rise at week 12 from baseline in both the groups. However, inter group analysis did not show any statistically significant change in LDL-C values at $12^{\text {th }}$ week between the groups, but the rise in HDL-C was more in group B when compared to group A.

Table 4: Changes in fasting plasma glucose (FPG) level in groups A and B at 4, 8 and 12 weeks from base line.

\begin{tabular}{|lllllll|}
\hline Parameter & & Week - & Week - 4 & Week - 8 & Week -12 & P value \\
\hline \multirow{2}{*}{ FPG $(\mathrm{mg} / \mathrm{dl})$} & Group A & $137.11 \pm 8.22$ & $122.64 \pm 6.61$ & $114.05 \pm 9.28$ & $111.88 \pm 8.55$ & $0.001(\mathrm{HS})$ \\
\cline { 2 - 8 } & Group B & $136.29 \pm 7.73$ & $110.35 \pm 7.18$ & $96.64 \pm 7.75$ & $85.94 \pm 8.06$ & $0.001(\mathrm{HS})$ \\
\hline
\end{tabular}

HS: Highly significant

Table 5: Changes in postprandial plasma glucose (PPG) level in groups A and B at 4, 8 and 12 weeks from base line.

\begin{tabular}{|lllllll|}
\hline Parameter & & Week - 0 & Week - 4 & Week - 8 & Week -12 & P value \\
\hline \multirow{2}{*}{ PPG (mg/dl) } & Group A & $227.52 \pm 9.64$ & $201.29 \pm 6.75$ & $190.41 \pm 6.04$ & $183.29 \pm 8.43$ & 0.001 (HS) \\
\cline { 2 - 8 } & Group B & $237.41 \pm 26.39$ & $169.94 \pm 22.92$ & $150.11 \pm 17.64$ & $139.23 \pm 17.62$ & 0.001 (HS) \\
\hline
\end{tabular}

HS: Highly significant

Table 6: Changes in LDL - C level in groups $A$ and $B$ at 12 weeks from base line.

\begin{tabular}{|lllll|}
\hline Parameter & & Week - 0 & Week - 12 & P - value \\
\hline \multirow{2}{*}{ LDL-C (mg/dl) } & Group A & $117.00 \pm 11.51$ & $102.41 \pm 9.30$ & 0.001 (HS) \\
\cline { 2 - 6 } & Group B & $117.88 \pm 11.78$ & $103.17 \pm 9.51$ & 0.001 (HS) \\
\hline
\end{tabular}

HS: Highly significant

Table 7: Changes in HDL - C level in groups A and B at 12 weeks from base line.

\begin{tabular}{|lllll|}
\hline Parameter & & Week - 0 & Week - 12 & P - value \\
\hline \multirow{2}{*}{ HDL-C (mg/dl) } & Group A & $54.11 \pm 8.03$ & $59.82 \pm 8.60$ & $0.001($ HS) \\
\cline { 2 - 6 } & Group B & $52.17 \pm 6.79$ & $60.23 \pm 6.72$ & $0.001(\mathrm{HS})$ \\
\hline
\end{tabular}

HS: Highly significant

\section{DISCUSSION}

Data from the above study suggest that there is significant reduction in Triglycerides and $\mathrm{HbA} 1 \mathrm{c}$ from their baseline values in both fenofibrate (group A) and saroglitazar group (group B). But there was no significant reduction in Triglyceride between the groups at $12^{\text {th }}$ week, however there was a significant reduction in $\mathrm{HbA} 1 \mathrm{C}$ in group $\mathrm{B}$ when compared to group $\mathrm{A}$ at $12^{\text {th }}$ week. This suggests that saroglitazar group has better 
glycaemic control when compared to fenofibrate group, which could be due to the additional PPAR - $\gamma$ agonistic action of this drug in addition to its PPAR - $\alpha$ agonistic action (Triglyceride lowering effect).

There was a significant reduction in FPG and PPG levels in both groups at 4,8 and 12 weeks from their pretreatment values. On inter group analysis saroglitazar group showed higher fall in FPG and PPG at each interval when compared to fenofibrate group which was statistically significant hence indicating better glycaemic control property with saroglitazar.

Levels of LDL - C and HDL - C showed statistically significant change at $12^{\text {th }}$ week from their respective baseline values in both the groups. However, inter group analysis did not show any statistically significant change in LDL-C values but there was a statistically significant rise in HDL-C in group B when compared to group A at $12^{\text {th }}$ week.

The clinical trials like PRESS V and PRESS VI have shown that saroglitazar decreased triglycerides by $45 \%$. In PRESS V study, saroglitazar decreased FPG and HbA1C levels significantly in a dose dependent manner and this decrease was similar to the efficacy of pioglitazone, also there was no significant alteration in body weights. ${ }^{13}$ PRESS VI study evaluated saroglitazar in patients with diabetic dyslipidemia inadequately controlled with statins. Results from PRESS VI study showed beneficial effects of saroglitazar on both lipid and glycaemic parameters. ${ }^{14}$ In this study saroglitazar has emerged as a drug that lowers both lipids and glucose in diabetic dyslipidemia with predominant Hypertriglyceridemia.

This study showed excellent safety profile with saroglitazar as only one patient showed GI disturbance on initiation of therapy which lasted for about 3-4 days. None of the patients were withdrawn from the study. There were no reports of serious life threatening adverse effects during the study.

\section{Limitations}

The study duration was relatively short for a period of 3 months and the sample size was small because of logistic problems.

\section{CONCLUSION}

The results of this randomized, open labeled phase IV study showed that addition of saroglitazar to metformin+ glimepiride in diabetic dyslipidemia reduced triglycerides, $\mathrm{HbA1C}$, FPG and PPG levels and the reduction in $\mathrm{HbA} 1 \mathrm{C}$, FPG and $\mathrm{PPG}$ was more when compared to addition of fenofibrate to metformin+ glimepiride.
Funding: No funding sources Conflict of interest: None declared

Ethical approval: The study was approved by the Institutional Ethics Committee

\section{REFERENCES}

1. Joshi SR, Parikh RM. India - diabetes capital of the world: now heading towards hypertension. J Assoc Physicians India. 2007;55:323-4.

2. Kumar A, Goel MK, Jain RB, Khanna P, Chaudhary V. India towards diabetes control: Key issues. Australas Med J. 2013;6(10):524-31.

3. Wild S, Roglic G, Green A, Sicree R, King H. Global prevalence of diabetes-estimates for the year 2000 and projections for 2030. Diabetes Care. 2004;27(3):1047-53.

4. Whiting, Guariguata L, Weil C, Shawj. IDF Diabetes atlas: Global estimates of the prevalence of diabetes for 2011 and 2030. Diabetes Res Clin Pract. 2011;94:311-21.

5. Muacevic-Katanec D, Reiner Z. Diabetic dyslipidaemia or diabetes lipidus? Expert Rev Cardiovasc Ther. 2011;9:341-48.

6. $\mathrm{Wu} \mathrm{L}$, Parhofer KG. Diabetic dyslipidaemia. Metabolism clinical and experimental. 2014;63:146979.

7. Brunzell JD, Davidson M, Furberg CD, Goldberg RB, Howard BV, Stein JH, et al. Lipoprotein management in patients with cardiometabolic risk: consensus statement from the American diabetes association and the American college of cardiology foundation. Diabetes Care. 2008;31(4):811-22.

8. Keech A, Simes RJ, Barter P, Best J, Scott R, Taskinen MR, et al. Effects of long-term fenofibrate therapy on cardiovascular events in 9795 people with type 2 diabetes mellitus (the FIELD study): randomised controlled trial. Lancet. 2005;366(9500):1849-61.

9. Rubenstrunk A, Hanf R, Hum DW, Fruchart JC, Staels B. Safety issues and prospects for future generations of PPAR modulators. Biochim Biophys Acta. 2007; 1771(8):1065-81.

10. Seber S, Ucak S, Basat O, Altuntas Y. The effect of dual PPAR alpha/gamma stimulation with combination of rosiglitazone and fenofibrate on metabolic parameters in type 2 diabetic patients. Diabetes Res Clin Pract. 2006;71(1):52-8.

11. Agrawal R. The first approved agent in the Glitazar's Class: Saroglitazar. Curr Drug Targets. 2014;15:1515 .

12. Aggarwal AS. India's answer to diabetic dyslipidaemia. Int $\mathrm{J}$ Pharmacol and Clin Sci. 2014;3:7-14.

13. Pai V, Paneerselvam A, Mukhopadhyay S, Bhansali A, Kamath D. A Multicenter, Prospective, Randomized, Double-blind Study to Evaluate the Safety and Efficacy of Saroglitazar 2 and $4 \mathrm{mg}$ Compared to Pioglitazone $45 \mathrm{mg}$ in Diabetic 
Dyslipidaemia (PRESS V). J Diabetes Sci Technol. 2014;8:132-41.

14. Jani RH, Pai V, Jha P, Jariwala G, Mukhopadhyay S. A multicenter, prospective, randomized, double-blind study to evaluate the safety and efficacy of Saroglitazar 2 and $4 \mathrm{mg}$ compared with placebo in type 2 diabetes mellitus patients having hypertriglyceridaemia not controlled with atorvastatin therapy (PRESS VI). Diabetes Technol Ther. 2014;16:63-71.

Cite this article as: Syed MA, Mujeeb MMA. A randomized comparative study of efficacy and safety of saroglitazar with fenofibrate in diabetic dyslipidemic patients on metformin and glimeperide. Int J Basic Clin Pharmacol 2017;6:1491-6. 